\title{
Challenging hepatitis C-infected liver transplant patients
}

This article was published in the following Dove Press journal:

Hepatic Medicine: Evidence and Research

18 January 2016

Number of times this article has been viewed

\author{
Madeleine Oliver ${ }^{\prime}$ \\ Christopher Chiodo Ortiz \\ Jorge Ortiz ${ }^{3}$ \\ 'University of Toledo College of \\ Medicine, Toledo, $\mathrm{OH},{ }^{2}$ Bucknell \\ University, Lewisburg, PA, \\ ${ }^{3}$ Department of Transplant Surgery, \\ University of Toledo Medical Center, \\ Toledo, OH, USA
}

\begin{abstract}
Caring for liver transplant patients suffering from chronic hepatitis $\mathrm{C}$ virus (HCV) infection is a challenging task for transplant surgeons and primary physicians alike. HCV is the leading cause of liver transplantation in the USA and comes with a myriad of complications that increase morbidity and mortality. This review focuses on patient follow-up, spanning from before the liver transplant occurs to the patient's long-term health. Pretransplant, both donor and recipient variables, must be carefully chosen to ensure optimal surgical success. Risk factors must be identified and HCV viral load must be reduced to a minimum. In addition to standard transplant complications, HCV patients suffer from additional problems, such as fibrosing cholestatic hepatitis and widespread viremia. Physicians must focus on the balance of immunosuppressive and antiviral medications, while considering possible side effects from these potent drugs. Over the years following surgery, physicians must identify any signs of failing liver health, as HCV-positive patients have an increased risk for cirrhosis and certain life-threatening malignancies.
\end{abstract}

Keywords: liver transplant, hepatitis $\mathrm{C}$ virus, postoperative, cirrhosis, donor and recipient variables, viremia

\section{Hepatitis $\mathbf{C}$ virus and the increasing need for liver transplants}

Chronic hepatitis $\mathrm{C}$ virus (HCV) infection is a global health problem that affects 130-150 million people worldwide. With a risk of progression to cirrhosis, liver failure, and hepatocellular carcinoma (HCC), it has resulted in 350,000 preventable deaths annually in the USA. ${ }^{1}$ On the US liver transplant wait list, $81 \%$ of the current HCV-positive patients comprise people born between 1941 and 1960. As these babyboomers continue to age over the next 20 years, the number of these HCV-related complications is expected to drastically increase. ${ }^{2}$ Within this generation, the need for liver transplants is ever-growing, and the search for the most effective transplant methods is ongoing.

The struggle begins before the transplant surgery occurs. Donor and recipient variables must be carefully accounted for to allow for the best possible outcome. Posttransplant, almost all HCV-positive patients experience recurrence of their infection. Some are able to control their disease, while others progress to fibrosis and may revert back to their pretransplant health status. Immunosuppressants used to treat all transplant patients and antiviral medications needed to control HCV have opposing effects on the human immune system. This review focuses on problems specific to those patients before the surgery, during postoperative care, and throughout the long-term health of the patient.
Correspondence: Madeleine Oliver University of Toledo College of Medicine, 3000 Arlington Ave,

Toledo, OH 436I4, USA

Tel +l 4193834000

Email madeleine.oliver@rockets.utoledo. edu submit your manuscript | www.dovepress.com

Dovepress

http://dx.doi.org/10.2147/HMER.S96110
Hepatic Medicine: Evidence and Research 2016:8 I-8

(c) (i) (5) 2016 Oliver et al. This work is published and licensed by Dove Medical Press Limited. The full terms of this license are available at https://www.dovepress.com/terms. BY NG php and incorporate the Creative Commons Attribution - Non Commercial (unported, v3.0) License (http://creativecommons.org//icenses/by-n/3.0/). By accessing the work you hission for cor timited, provided the work is properly attributed. To permission for commercial use of this work, please see paragraphs 4.2 and 5 of our Terms (https://www.dovepress.com/terms.php). 
Table I All liver transplant patients

\begin{tabular}{|c|c|c|}
\hline Condition & Symptoms & Treatment \\
\hline Primary nonfunction & $\begin{array}{l}\text { - Mild coagulopathy, oliguria, jaundice, and hypoglycemia } \\
\text { - Liver transaminases higher than 5,000 U/L }\end{array}$ & - Immediate retransplant \\
\hline Preservation injury & $\begin{array}{l}\text { - Rising liver transaminases, hyperbilirubinemia } \\
\text { - Poor synthetic function } \\
\text { - Prolonged prothrombin time } \\
\text { - Impaired clearance of ammonia }\end{array}$ & - Supportive care and avoidance of infection \\
\hline Small-for-size syndrome & $\begin{array}{l}\text { - Portal hypertension leading to cholestasis, } \\
\text { poor bile production } \\
\text { - Susceptibility to sepsis }\end{array}$ & - Supportive care and avoidance of infection \\
\hline Hepatic artery thrombosis & $\begin{array}{l}\text { - Rapid hepatic dysfunction leading to stricture, biliary leak } \\
\text { - Can rapidly progress to multiorgan failure }\end{array}$ & $\begin{array}{l}\text { - Surgical or radiologic revascularization; severe } \\
\text { cases may need retransplant }\end{array}$ \\
\hline Portal vein thrombosis & $\begin{array}{l}\text { - Ascites } \\
\text { - Increased portal vein pressure }\end{array}$ & $\begin{array}{l}\text { - Mechanical or pharmacological thrombolysis for } \\
\text { less severe cases; portal vein thrombectomy or } \\
\text { retransplant with severe cases }\end{array}$ \\
\hline Biliary leak & - Constant biliary leak, bilious ascites, and biloma & $\begin{array}{l}\text { - Endoscopic retrograde } \\
\text { cholangiopancreatography and stent placement }\end{array}$ \\
\hline Biliary stricture and stenosis & $\begin{array}{l}\text { - Fever, jaundice, sepsis, and severe cholestasis } \\
\text { - Histologically, bile duct dilatation, cholangitis, } \\
\text { and periductal fibrosis are observed }\end{array}$ & $\begin{array}{l}\text { - Primary treatment is antibiotics and patient } \\
\text { stabilization } \\
\text { - May require retransplant in severe cases }\end{array}$ \\
\hline Acute cellular rejection & $\begin{array}{l}\text { - Abnormal liver enzymes, hyperbilirubinemia } \\
\text { - Histologically, within endothelial cells, symptoms of inflammation, } \\
\text { bile duct damage, and inflammatory infiltrate are observed }\end{array}$ & $\begin{array}{l}\text { - Maintenance immunosuppression for mild cases } \\
\text { and high doses of steroids, antilymphocyte } \\
\text { preparations for severe cases }\end{array}$ \\
\hline
\end{tabular}

\section{Preoperative variables}

When caring for the postorthotopic liver transplant (POLT) $\mathrm{HCV}$ patient, several donor and recipient variables must be considered for optimal transplant success. The indications for transplant and symptoms of liver failure must be elucidated. These include ascites, gastrointestinal bleeding, varices, hepatic encephalopathy, and the effects of poor nutrition. Using the Model for End-Stage Liver Disease (MELD) score, it is possible to quantify the overall health of the patient's liver using serum creatinine, bilirubin, and international

Table 2 HCV-specific complications

\begin{tabular}{lll}
\hline Condition & Symptoms & Treatment \\
\hline Fibrosing & - Rapid liver dysfunction, fibrosis & Antiviral \\
cholestatic & - Elevated alkaline phosphatase, & medications \\
hepatitis & serum bilirubin, and high & \\
& HCV-RNA levels & \\
& - Histologically, severe & \\
& cholestasis, hepatocyte & \\
& swelling, and sinusoidal fibrosis & \\
Posttransplant & are observed & \\
diabetes & Symptoms of diabetes plus & Standard diabetes \\
mellitus & Casual plasma/2-hour plasma & mellitus therapy \\
& glucose concentrations & \\
& $\geq 200$ mg/dL & \\
& Fasting plasma glucose & \\
\hline
\end{tabular}

Abbreviation: $\mathrm{HCV}$, hepatitis $\mathrm{C}$ virus. normalized ratio of prothrombin time. The MELD score, which is adjusted for certain cases such as advanced HCC, can shed light on the patient's short-term prognosis. This score allows the United Network for Organ Sharing to prioritize patients for transplantation. ${ }^{3}$ After both clinical and laboratory evaluation, it can be decided if a liver transplant is the next best step for the patient.

Donor variables, such as age and allograft source, have an effect on the recurrence and severity of $\mathrm{HCV}$ posttransplant. Donations from people over 50 years old progress to fibrosis and cirrhosis sooner than allografts from younger donors. ${ }^{4}$ A living donor can have an impact on transplant success as well. One study found that recipients of right lobe living donor transplants demonstrated a $10 \%$ better survival rate than those patients receiving deceased-donor livers. These patients were able to receive their transplant sooner, at a healthier state, and with lower MELD scores than patients receiving deceased-donor livers. ${ }^{5}$

The donor's cause of death has some bearing on patient survival as well. Ischemic-reperfusion injury occurs after prolonged hypoxia and subsequent restoration of oxygen supply. Ischemia can be a result of storage of the liver before transplantation, known as cold ischemic time, or interruption of blood supply during transplantation, referred to as warm ischemic time. Both prolonged ischemic time and reperfusion injury can compromise liver function and cause 
recovery complications and poorer outcomes. ${ }^{6}$ Donation after brain death is the primary choice for an allograft, but with an increasing need for organs, donation after cardiac death is often used. After cardiac death, warm ischemic time increases. Many studies have revealed decreased patient survival in donation after cardiac death recipients. ${ }^{7}$

Another factor to consider when evaluating potential organ donors is the use of $\mathrm{HCV}$-infected organs. Today, a major organ shortage exists due to an increased incidence of vital organ failure and more successful transplant outcomes. This shortage must be addressed quickly, as the number of patients on transplant lists and the number of patients dying while waiting are steadily increasing. Currently, HCVpositive donor (HCVD+) grafts are limited to HCV-infected recipients. Montenovo et $\mathrm{al}^{8}$ found the use of $\mathrm{HCVD}+$ grafts in HCV-positive recipients resulted in equally successful outcomes as HCV-negative donor grafts. Unfortunately, risks in using these organs still exist. An HCVD+ graft may progress to fibrosis in the presence of immunosuppression or the recipient may encounter a new strain of the virus within the graft. However, these concerns are diminished with modern anti-HCV therapy including direct-acting agents (DAAs), which will be discussed further in later sections. ${ }^{8,9}$

Donor and recipient genetics contribute to the success of the liver transplant. The interleukin-28B (IL-28B) gene, which can be determined pretransplant, influences posttransplant liver function and response to treatment. The IL-28B gene encodes a type of interferon, crucial in the overall inflammatory response to a viral infection. Donor-CC genotype recipients have increased liver enzymes, viral load, and rate of fibrosis, along with adverse outcomes such as cirrhosis and need for retransplantation. However, recipient-CC genotype has the exact opposite results - less overall fibrosis and better outcomes. Overall, the combination of both donor- and recipient-CC genotype had a higher sustained viral response rate, indicating better response to antiviral medications. ${ }^{10,11}$ The IL-28B gene provides a direction for future research to find ways to personalize HCV treatments for specific patient genetics.

Germane recipient variables must be identified before surgery. Bone disease, specifically osteoporosis, is a legitimate concern for any transplant patient. Screening for osteoporosis and related diseases can be done using a bone densitometry test before the surgery. Additionally, any chronic health issues such as diabetes or cardiovascular disease must be documented and monitored postsurgery. Many HCV-infected patients also suffer from intravenous drug abuse, drinking, or smoking, which can cause malignancy and poor outcomes.
These patients are encouraged to abstain from drugs, alcohol, and tobacco to reduce the likelihood of head and neck cancers, HCC, and liver dysfunction. ${ }^{12}$

All HCV-positive transplant patients should reduce their viral load to a minimum in order to discourage immediate posttransplant viral recurrence. Whether the infection has progressed to cirrhosis, HCC, or hepatic decompensation, the primary goal is to treat the HCV infection and stabilize the patient. It is important to improve the rates of sustained virological response (SVR), (defined as rendering a patient aviremic 12 or more weeks after completion of antiviral therapy). ${ }^{13}$ Currently, the standard treatment of combination therapy, including DAA, pegylated interferon, and ribavirin are prescribed to most patients on the liver transplant list suffering from $\mathrm{HCV}^{14}$

Unfortunately, viral treatment is not always an easy task for physicians. The $\mathrm{HCV} 1 \mathrm{a}$ and $1 \mathrm{~b}$ genotypes, the most common in the USA, have been linked to posttransplant complications, including fibrosis, acute and chronic hepatitis, and cirrhosis. Some believe that the HCV $1 \mathrm{~b}$ genotype is better used to determine treatability with antivirals rather than posttransplant complications. Those with genotype $\mathrm{HCV} 1 \mathrm{~b}$ have less of a response to interferon-based antiviral treatments. ${ }^{15}$ Because of this lack of response to standard therapy, new treatments such as protease inhibitors have been introduced to help these patients with HCV both pre- and posttransplant. Preliminary results are promising; however, significant side effects and drug-drug interactions have proven to be a problem and will be discussed later. ${ }^{16}$

\section{Normal postoperative care and management}

Immediately following surgery, most transplant patients are monitored in the intensive care unit while intubated and anesthetized until they are stable and ready for transfer. Any technical issues during the operation should be noted. The length of case, ischemic time, and blood loss affect graft function and patient recovery. Liver health can be monitored through normalizing prothrombin time, improving total bilirubin and liver transaminase level, resolving hypothermia, and improving mental status. Adequate urine output and resolving acidosis indicate good kidney and strong graft function. $^{17}$

Standard monitoring includes electrocardiography and pulse oximetry to measure cardiovascular function, as well as pulmonary artery pressure, arterial pressure, respiration, and core body temperature. Neurological capacity should be assessed through the patient's level of consciousness, 
cranial nerve reflexes, and motor-sensory function. Those in care of the patient should be wary of any indications of neurological compromise such as headaches, paresthesia, seizures, and coma. ${ }^{17}$

Additionally, hemodynamic monitoring is crucial, although it is important to note key differences between transplant patients and the norm. Low blood volume from preexisting cardiovascular problems, ascites, hemorrhage, or edema can cause poor graft perfusion, increasing the likelihood for graft complications. In order to avoid excess administration of fluids, optimizing cardiac output is a priority. Maintenance of strong cardiac output and normal fluid levels help prevent problems in the hepatic circulatory system caused by pulmonary edema and increased blood pressure. Electrolyte imbalances are common, as many transplant patients suffer from poor nutritional status before surgery and are given blood transfusions and diuresed during surgery. Given that many transplant medications can exacerbate these imbalances, they are important to monitor throughout recovery. ${ }^{18}$

Within the first week, early liver dysfunction may develop and certain protocols must be followed in order to correctly diagnose the problem. For all transplant patients, graft failure, structural problems, biliary complications, and graft rejection must be considered and investigated to treat the patient properly (Table 1). Problems specific to HCV patients will be discussed later.

During the immediate postoperative period, graft failure with no obvious cause is referred to as primary nonfunction. The patient may display mild symptoms such as coagulopathy, oliguria, jaundice, and hypoglycemia. It could present more severely with neurological setbacks and coma. Liver transaminases may reach levels higher than 5,000 U/L. The only definitive therapy for these patients is immediate retransplant. ${ }^{19}$ Preservation injury, another type of graft dysfunction, occurs within 72 hours posttransplantation. Differing from nonfunction, it is less severe and has a higher probability of recovery. Despite treatment with fresh frozen plasma, patients show rising liver transaminases, poor synthetic function, and prolonged prothrombin time. Additional problems include hyperbilirubinemia and impaired metabolic clearance of ammonia. With supportive therapy and careful avoidance of infection, preservation injury begins to resolve in 3 days without retransplantation. ${ }^{17}$

Structural problems can arise from size discrepancies between the donor artery and other native vessels. Small-forsize syndrome occurs mostly with partial liver grafts from a live donor or a split liver. Hemodynamic congestion and portal hypertension cause cholestasis, poor bile production, and susceptibility to many complications, namely sepsis. Hepatic artery thrombosis, a relatively uncommon complication at $3 \%-5 \%$, is potentially life threatening. ${ }^{18}$ During the early postoperative period, it presents as rapid hepatic dysfunction and can include other hepatic complications such as stricture, biliary leak, and multiorgan failure. Diagnosis with a Doppler ultrasound is necessary. It is confirmed with angiography. Treatment with surgical or radiologic revascularization is usually appropriate. If this fails, retransplant may be necessary. ${ }^{20}$

Portal vein thrombosis (PVT) has an incidence in up to $10 \%$ of patients and occurs commonly in those with technical problems or with preexisting PVT. Sudden symptoms like ascites and increased portal vein pressure indicate PVT. Preliminary diagnosis is done with ultrasound, and confirmed with magnetic resonance imaging or computed tomography scan. If severe hepatic ischemia occurs, immediate portal vein thrombectomy or retransplant is necessary. In less severe cases, the preferred treatment is thrombolysis, either mechanically or pharmacologically. ${ }^{21}$

Biliary complications are one of the major obstacles in liver transplant, occurring in up to $50 \%$ of patients. Leaks from the biliary tract are discovered early in the postoperative period, resulting from necrosis at the anastomosis of the donor and recipient bile ducts. Symptoms can include bilious ascites, constant bile drainage, and biloma. Ultrasound is the standard diagnostic tool and treatment may require endoscopic retrograde cholangiopancreatography and stent placement. These leaks may progress to serious systemic infection and must be closely monitored. On the other hand, biliary stricture and stenosis present with fever, jaundice, sepsis, and severe cholestasis. ${ }^{22,23}$ Histologically, bile duct dilatation, cholangitis, and periductal fibrosis will be seen. ${ }^{24}$ These patients can progress to secondary organ failure, impairing cardiovascular, renal, and pulmonary function. The primary treatment focuses on antibiotics and patient stabilization. In some severe cases, patients may require retransplant. $^{22}$

As with any transplant surgery, a major concern is rejection. Differences in donor and recipient leukocyte antigens cause inflammation of the allograft and graft dysfunction. In the first 30 days, the most common form is acute cellular rejection, a function of T-cell-mediated injury to the vascular endothelium and bile ducts of the liver. ${ }^{17}$ Abnormal liver enzymes and hyperbilirubinemia indicate acute rejection, and a percutaneous or transjugular liver biopsy should be obtained. Histologically, portal inflammation, bile duct damage, and inflammatory infiltrate 
to endothelial cells can be seen. Solely signs of inflammation point toward a quick diagnosis, but there must be other proof of rejection before the diagnosis can be confirmed. ${ }^{25}$ Standard treatment for mild rejection includes robust maintenance immunosuppression with calcineurin inhibitors or other agents. If rejection becomes more severe, high doses of steroids and antilymphocyte preparations must be used. ${ }^{26}$ This aggressive treatment proves to be a problem for $\mathrm{HCV}$-positive patients, as it leads to increased severity and frequency of $\mathrm{HCV}$ recurrence. When treating these patients, the least number of drugs at the lowest dose is the gold standard, as long as sufficient immunosuppression is reached. ${ }^{27}$

Infection poses a significant risk during the postoperative period, occurring in up to $80 \%$ of transplant patients. Most infections are endogenous from gastrointestinal flora. Infection risk increases with recipient malnutrition or advanced liver disease, preexisting donor infection, and surgical complications such as retransplantation or prolonged surgery times. The greatest risk of infection (and HCV recurrence) coincides with the highest doses of immunosuppressive medications, as with acute rejection patients. ${ }^{28}$

\section{HCV-specific complications}

HCV-specific complications are shown in Table 2. Most transplant patients with an existing $\mathrm{HCV}$ infection exhibit immediate reinfection with widespread viremia, sometimes exceeding pretransplant HCV-RNA levels. The infection may progress more rapidly in patients posttransplant than those not undergoing a liver transplant. ${ }^{29}$

Fibrosing cholestatic hepatitis (FCH) is an early, vicious, recurrence of $\mathrm{HCV}$ after a liver transplant differing from general viremia. Occurring in less than $10 \%$ of the patients with chronic $\mathrm{HCV}$, those suffering from $\mathrm{FCH}$ have a much higher risk of mortality. Within 2 years, FCH causes rapid liver dysfunction, leading to fibrosis and graft loss. ${ }^{30}$ Therefore, it is crucial to differentiate this HCV-specific complication from acute or chronic rejection. Lab findings include elevated alkaline phosphatase and serum bilirubin and high serum HCV-RNA levels. ${ }^{31}$ Signs can be seen within the first 6 months after transplantation. Due to similar clinical symptoms, biopsy findings are imperative in differentiating FCH from acute rejection. Histologically, severe cholestasis, hepatocyte swelling, and advanced sinusoidal fibrosis are found. Conversely, the primary finding in acute rejection is severe biliary epithelium damage and inflammatory infiltrate surrounding vascular endothelium. If $\mathrm{FCH}$ is incorrectly diagnosed as acute rejection, immunosuppressive treatment can cause serious side effects in the patient. ${ }^{24,32}$ In addition to antiviral medications, treatment for $\mathrm{FCH}$ includes interferon therapy or the newer anti-HCV agents. ${ }^{31}$

The liver is necessary for proper glucose metabolism, thus liver dysfunction can lead to insulin resistance and type II diabetes mellitus (DM). Transplant patients are already predisposed to insulin resistance due to the side effects of immunosuppressive medications such as steroids and calcineurin inhibitors. Additionally, $\mathrm{HCV}$ is an independent risk factor for posttransplant diabetes mellitus (PTDM). PTDM frequently develops simultaneously with HCV recurrence, indicating a possible link between viral replication and poor glycemic control. Immunosuppressive drugs, namely steroids and calcineurin inhibitors, have a compounding effect. Alone, they are diabetogenic, allowing increased viral replication, further increasing the likelihood for DM to develop. ${ }^{33} \mathrm{HCV}$ increases the chances of PTDM and the resulting insulin resistance increases the severity of $\mathrm{HCV}$ recurrence. ${ }^{34}$ PTDM is also associated with higher rates of mortality among transplant recipients due to increased incidence of acute rejection in the 2 -year period following the transplant. ${ }^{35}$

\section{The complication of medications}

The administration of antirejection medications must coincide with careful monitoring of potential side effects. Tacrolimus, a calcineurin inhibitor, slows the activation of T-cells, the main mediator of allograft rejection. Several side effects, mainly nephrotoxicity and neurotoxicity, can cause increased morbidity and mortality posttransplant. Mycophenolate mofetil, an antimetabolite, can cause bone marrow suppression resulting in neutropenia and gastrointestinal toxicity. Corticosteroids are a main cause of diabetes, osteoporosis, hypertension, and psychiatric disorders. ${ }^{36}$

Additionally, patients must be treated prophylactically for infections that may arise under immunosuppressive therapy. Cytomegalovirus, an opportunistic viral infection, must be preemptively prophylaxed with valacyclovir. Pneumocystis, a severe pulmonary infection, must be treated with Bactrim. Both of these medications cause neutropenia, which must be monitored throughout patient care. In the incidence of an infection, immunosuppressant doses must be lowered until the patient is stable. ${ }^{36}$

With a detectable HCV viral load pretransplant, the chance of recurrence is practically universal, and treatment is necessary to prevent further complications, such as cirrhosis. ${ }^{37}$ Those suffering from latent $\mathrm{HCV}$ have a $50 \%-80 \%$ chance for $\mathrm{HCV}$ reinfection posttransplant and their viral load must be monitored to determine if, and when, it occurs. ${ }^{36}$ Currently, two schools of thought exist in 
regard to the proper timing of treatment. Some believe in "preemptive treatment", meaning antiviral medications are prescribed immediately after surgery under the assumption that recurrence will occur in all patients. This method of treatment is fairly outdated; the protocol today is to begin treatment once there is a diagnosed, established recurrence of HCV infection. This diagnosis can be made with alanine aminotransferase elevation, positive $\mathrm{HCV}$-polymerase chain reaction test, or histological evidence in a liver biopsy. Other reasons for graft failure, as discussed before, must be ruled out if any uncertainty exists. ${ }^{13}$

Interferon and ribavirin were the most commonly used medications for posttransplant viral recurrence; however, they showed poor efficacy in this setting. Furthermore, the risk of acute and chronic rejection increased due to upregulation of the immune system through the mechanism of interferon. ${ }^{15}$ As per the European Association for the Study of the Liver guidelines, the current standard treatment involves combination therapy, using both interferon and ribavirin, along with other antivirals. DAA, such as telaprevir and boceprevir act as protease inhibitors, reversibly binding to HCV-nonstructural proteins. These drugs show increased efficacy, specifically against HCV genotype 1 patients. Newer DAAs, including sofosbuvir, simeprevir, and daclatasvir, have recently been approved for combination therapy against HCV genotypes 1 and $4 .{ }^{14}$ However, due to the high cost of these medications, along with severe drug-drug interactions with immunosuppressants, their use is limited. The continued use of interferon and ribavirin in combination therapy leads to several severe side effects. Patients suffer from anemia, and may require erythropoietin therapy to stimulate red blood cell growth. More prominent in those with severe hepatitis, symptoms of fatigue, pyrexia, and cytopenias are evident. ${ }^{13}$

Due to side effects and low success rates in treating HCV genotype 1 patients, interferon-free regimens have been introduced. Combination therapy with sofosbuvir and ledipasvir, with and without ribavirin, has shown promising results. In both fibrotic and nonfibrotic $\mathrm{HCV}$ genotype 1 patients, this treatment plan resulted in over $90 \%$ SVR. ${ }^{38}$ These new treatments offer an alternate cure to transplantation, and are especially important for those who are not transplant eligible. These new DAA combination therapies are the future of anti-HCV therapy and could possibly lead to complete eradication of the disease. ${ }^{39}$

HCV genotype 3 patients have been less successful following the DAA combination therapy regimen, and have appeared to be the most difficult to treat with interferon-free DAA combinations. ${ }^{38} \mathrm{HCV}$ genotype 3 accounts for $40 \%$ of all HCV cases in Asia and majority of HCV cases for intravenous drug users worldwide. When interferon and ribavirin were the standard treatment, HCV genotype 3 was considered an "easily treatable" disease. With anti-HCV therapy moving toward DAA combination therapy and interferon-free treatment, HCV genotype 3 has become increasingly harder to treat. Considering the sheer number of patients suffering from this specific strain of $\mathrm{HCV}$, and its propensity to progress to severe liver disease, developing therapy has been a pressing issue among researchers. ${ }^{40}$

While great strides have been made in finding a cure for $\mathrm{HCV}$, many patients suffering from this disease find that the new treatment regimens are difficult to access. Currently, DAA and interferon-free therapy are provided for patients who have not responded to interferon-based treatments, with cirrhosis, on the liver transplant list, and in the posttransplant setting. Due to the high cost of these drugs, many patients are unable to afford these drugs unless universal health care is granted. Since it has been established that these drugs can possibly eradicate the disease and potentially avoid liver transplantation, it becomes increasingly important to find ways to allow all patients access. ${ }^{41}$

\section{Long-term care}

Recipients must be monitored for a myriad of comorbidities for the remainder of their lives. Long-term complications range from controllable cardiovascular diseases to lifethreatening malignancies. Standard screening techniques can be utilized to treat these patients effectively and quickly. Cardiovascular disease causes $20 \%$ of long-term deaths in transplant patients. While often caused by risk factors beyond a patient's control, such as sex, family history, and advanced age, certain risk factors can be avoided. Hypertension, a common side effect of immunosuppressant medications, can be treated per the standard guidelines for nontransplant patients. Hyperlipidemia and obesity, often comorbidities with cholestatic liver disease and diabetes, can be treated through lifestyle modifications and first-line statin medications. ${ }^{36}$

Renal disease, a complication for $20 \%$ of liver transplant patients, can be monitored through creatinine levels and glomerular filtration rates. Elevated creatinine is a risk factor for end-stage renal disease. Patients with early renal dysfunction - including acidosis and oliguria posttransplant must be closely monitored. Nephrotoxic agents, specifically calcineurin inhibitors, must be reduced or eliminated from patient treatment upon apparent nephrotoxicity. Bone disease should be screened for before, and up to 5 years after, 
the transplant. Preexisting conditions such as osteoporosis, vitamin D deficiency, and hypogonadism can contribute to future developments of bone disease. As a result of transplant treatment with corticosteroids, bone mass greatly decreases and should be monitored throughout posttransplant care. ${ }^{36}$

Any signs of liver decompensation indicated pretransplant must be monitored throughout the patient's continuing care. Ascites should resolve with improved graft function and through diuresis used to treat hypertension. A patient may never fully recover from any neurological deficits from hepatic encephalopathy pretransplant, but neurological function should not decline with a healthy allograft. Any patient who suffered from intravenous drug, alcohol, or tobacco use pretransplant must abstain from these substances throughout his or her recovery. ${ }^{12}$

Malignancy remains the highest cause of morbidity and mortality in liver transplant patients. Overall, up to $12.9 \%$ of liver transplant patients suffer from some kind of cancer, ranging from posttransplant lymphoproliferative disorders to oropharyngeal malignancies. Patients should undergo ageappropriate screening for cancer, in addition to appropriate checkups for any health concerns. ${ }^{12}$ Half of all new malignancies are skin cancer, and patients are advised to visit a dermatologist for any suspicious skin lesions posttransplant. Sunscreen is advised. ${ }^{42}$ Furthermore, HCV-positive patients are at a much higher risk for HCC than most undergoing a liver transplant. ${ }^{37}$ While existing HCC should be cured with a liver transplant, recurrence of malignancy is possible. The standard test is abdominal and chest imaging every 6 months for the 3 years following surgery. Any lesion discovered should be properly biopsied and diagnosed. Lab measurements of $\alpha$-fetoprotein can be used to monitor previously occurring HCC. ${ }^{12}$

Specifically for HCV-positive patients, viral recurrence is an ongoing issue. While all HCV-positive patients suffer from continued infection posttransplant, $75 \%$ of patient cases result in clinical hepatitis, ${ }^{15} 20 \%-30 \%$ of these patients with clinical hepatitis progress to cirrhosis within 5 years posttransplant. Patients who develop cirrhosis have a $42 \%$ chance of liver decompensation within the next year. ${ }^{43}$ While most transplant patients have permanently elevated liver enzymes, if the primary physician notices above-baseline liver enzymes levels or poor liver function tests, further investigation is needed. Late allograft rejection, reactivation of a latent infection such as cytomegalovirus and technical issues are common possibilities. Biopsies, imaging, ultrasound, and $\mathrm{HCV}$-polymerase chain reaction testing can help diagnose the cause of hepatic decompensation. ${ }^{42}$
In the event of a severe recurrence of $\mathrm{HCV}$, antiviral medications must be started immediately to reduce the viral load to manageable levels. With uncontrolled infections, $\mathrm{HCV}$ can progress to cirrhosis and the patient's health will return to pretransplant status. In the event that the primary care physician establishes signs of liver decompensation, the transplant center must be notified. Severe recurrence is an indication for elective liver retransplant; however, this treatment is controversial and its long-term efficacy is unproven. ${ }^{44}$ Throughout the ongoing treatment for the patient, communication between the primary care physician and transplant center is crucial.

HCV remains the leading indication for liver transplant in the USA and will be in the foreseeable future. Primary care physicians and transplant surgeons alike have made strides in caring for $\mathrm{HCV}$-infected patients. New standards of antiviral medications and awareness of unique complications have improved transplant outcomes; however, the challenging task of caring for an $\mathrm{HCV}$-infected liver transplant patient remains. Before the surgery, during postoperative care, and throughout the patient's long-term health, it is important to correctly diagnose complications, treat carefully, and screen for comorbidities to ensure an optimal outcome for the patient.

\section{Disclosure}

The authors report no conflicts of interest in this work.

\section{References}

1. Verna EC, Valadao R, Farrand E, et al. Effects of ethnicity and socioeconomic status on survival and severity of fibrosis in liver transplant recipients with hepatitis C virus. Liver Transpl. 2012;18(4):461-467.

2. Biggins SW, Bambha KM, Terrault NA, et al. Projected future increase in aging HCV-infected liver transplant candidates: a potential effect of HCC. Liver Transpl. 2012;18(12):1471-1478.

3. Al Sibae MR, Mitchell SC. Accuracy of MELD scores in predicting mortality in decompensated cirrhosis from variceal bleeding, hepatorenal syndrome, alcoholic hepatitis, or acute liver failure as well as mortality after non-transplant surgery or TIPS. Dig Dis Sci. 2011;56(4): 977-987.

4. Wali M, Harrison RF, Gow PJ, Mutimer D. Advancing donor liver age and rapid fibrosis progression following transplantation for hepatitis $\mathrm{C}$. Gut. 2002;51(2):248-252.

5. Shah SA, Levy GA, Grieg PD, et al. Reduced mortality with right-lobe living donor compared to deceased-donor liver transplantation when analyzed from the time of listing. Am J Transplant. 2007;7(4):998-1002.

6. Li J, Li RJ, Lv GY, Liu HQ. The mechanisms and strategies to protect from hepatic ischemic-reperfusion injury. Eur Rev for Med and Pharmaco Sci. 2015;19(11):2036-2074.

7. Jay C, Ladner D, Wang E, et al. A comprehensive risk assessment of mortality following donation after cardiac death liver transplant - an analysis of the national registry. $J$ Hepatol. 2011;55(4):808-813.

8. Montenovo MI, Dick AA, Hansen RN. Donor hepatitis C sero-status does not impact survival in liver transplantation. Ann Transplant. 2015;20: $44-50$. 
9. Coilly A, Samuel D. Pros and cons: usage of organs from donors infected with hepatitis $\mathrm{C}$ virus - revision in the direct-acting antiviral era. J Hepatol. 2015. DOI: http://dx.doi.org/10.1016/j.jhep.2015.09.002.

10. deLemos AS, Schmeltzer PA, Russo MW. Recurrent hepatitis C after liver transplant. World J Gastroenterol. 2014;20(31):10668-10681.

11. Biggins SW, Trotter J, Gralla J, et al. Differential effects of donor and recipient IL28B and DDX58 SNPs on severity of HCV after liver transplantation. J Hepatol. 2013;58(5):969-976.

12. American Association for the Study of Liver Diseases. Hepatitis C guidance: AASLD-IDSA recommendations for testing, managing, and treating adults infected with hepatitis C virus. Hepatology. 2015;62(3): 932-954.

13. Joshi D, Carey I, Agarwal K. Review article: the treatment of genotype 1 chronic hepatitis $\mathrm{C}$ virus infection in liver transplant candidates and recipients. Aliment Pharmacol Ther. 2013;37(7):659-671.

14. European Association for the Study of the Liver. EASL recommendations on treatment of hepatitis C. J Hepatol. 2015;63(1):199-236.

15. Sheiner PA. Hepatitis C after liver transplantation. Semin Liver Dis. 2000;20(2):201-209.

16. Gane EJ, Agarwal D. Directly acting antivirals (DAAs) for the treatment of chronic hepatitis $\mathrm{C}$ virus infection in liver transplant patients: “A flood of opportunity”. Am J Transplant. 2014;14(5):994-1002.

17. Rudow DL, Goldstein MJ. Critical care management of the liver transplant recipient. Crit Care Nurs Q. 2008;31(3):232-243.

18. Feltracco P, Barbieri S, Galligioni H, Michieletto E, Carollo C, Ori C. Intensive care management of liver transplanted patients. World $J$ Hepatol. 2011;3(3):61-71.

19. Manzarbietia C. Practical Manual of Abdominal Organ Transplantation. New York: Kluwer Academic/Plenum Publishers; 2002.

20. Mourad MM, Liossis C, Gunson BK, et al. Etiology and management of hepatic artery thrombosis after adult liver transplant. Liver Transpl. 2014;20(6):713-723.

21. Feltracco P, Barbieri S, Cillo U, Zanus G, Senzolo M, Ori C. Perioperative thrombotic complications in liver transplantation. World J Gastroenterol. 2015;21(26):8004-8013.

22. Mueller AR, Platz KP, Kremer B. Early postoperative complications following liver transplantation. Best Pract Res Clin Gastroenterol. 2004;18(5):881-900.

23. Simoes P, Kesar V, Ahmad J. Spectrum of biliary complications following live donor liver transplantation. World J Hepatol. 2015;7(14): 1856-1865.

24. Salamao M, Verna EC, Lefkowitch JH, Moreira RK. Histopathologic distinction between fibrosing cholestatic hepatitis $\mathrm{C}$ and biliary obstruction. Am J Surg Pathol. 2013;37(12):1837-1844.

25. Burton JR, Rosen HR. Acute rejection in HCV-infected liver transplant recipients: the great conundrum. Liver Transpl. 2006;12(11 Suppl 2): S38-S47.

26. Samonakis DN, Germani G, Burroughs AK. Immunosuppression and HCV recurrence after liver transplantation. J Hepatol. 2012;56(4): 973-983.

27. Terrault N. Liver transplantation in the setting of chronic HCV. Best Pract Res Clin Gastroenterol. 2012;26(4):531-548.
28. Faguioli S, Colli A, Bruno R, et al. Management of infections pre- and post-liver transplantation: report of an AISF consensus conference. J Hepatol. 2014;60(5):1075-1089.

29. Grassi A, Ballardini G. Post-liver transplant hepatitis C virus recurrence: an unresolved thorny problem. World J Gastroenterol. 2014;20(32): 11095-11115.

30. Kim B, Trivedi A, Thung SN, Grewal P. Case report of successful treatment of fibrosing cholestatic hepatitis $\mathrm{C}$ with sofosbuvir and ribavirin after liver transplant. Semin Liver Dis. 2014;34(1):108-112.

31. Cimsit B, Assis D, Caldwell C, et al. Successful treatment of fibrosing cholestatic hepatitis after liver transplant. Transplant Proc. 2011;43(3): 905-908.

32. Dixon LR, Crawford JM. Early histologic changes in fibrosing cholestatic hepatitis. Liver Transpl. 2007;13(2):219-226.

33. Baid S, Cosimi AB, Farrel ML, et al. Posttransplant diabetes mellitus in liver transplant recipients: risk factors, temporal relationship with hepatitis $\mathrm{C}$ virus allograft hepatitis, and impact on mortality. Transplantation. 2001;72(6):1066-1072.

34. Morbitzer KA, Taber DJ, Pilch NA, et al. The impact of diabetes mellitus and glycemic control on clinical outcomes following liver transplant for hepatitis C. Clin Transplant. 2014;28(8):862-868.

35. Pageaux GP, Faure S, Bouyabrine H, Bismuth M, Assenat E. Longterm outcomes of liver transplantation: diabetes mellitus. Liver Transpl. 2009;15 Suppl 2:S79-S82.

36. Levitsky J, Cohen SM. The liver transplant recipient: what you need to know for long-term care. J Fam Practice. 2006;55(2):136-144.

37. Coilly A, Roche B, Duclos Vallee JC, Samuel D. Optimal therapy in hepatitis $\mathrm{C}$ virus liver transplant patients with direct acting antivirals. Liver Int. 2015;35 Suppl 1:44-50.

38. Holmes JA, Thompson AJ. Interferon-free combination therapies for the treatment of hepatitis C: current insights. Hepat Medicine. 2015;7: $51-70$.

39. Wilder JM, Muir AJ. Strategies for treating chronic HCV infection in patients with cirrhosis: latest evidence and clinical outcomes. Ther Adv Chronic Dis. 2015;6(6):314-327.

40. Gondeau C, Pageaux GP, Larrey D. Hepatitis C virus infection: are there still specific problems with genotype 3? World J Gastroenterol. 2015;21(42):12101-12113.

41. Fung J. Era of direct acting antivirals in chronic hepatitis C: who will benefit? World J Hepatol. 2015;7(24):2543-2550.

42. Singh S, Watt KD. Long-term medical management of the liver transplant recipient: what the primary care physician needs to know. Mayo Clin Proc. 2012;87(8):799-790.

43. Ponziani FR, Milani A, Gasbarrini A, et al. Treatment of genotype-1 hepatitis $\mathrm{C}$ recurrence after liver transplant improve survival in both sustained responders and relapsers. Transplant Int. 2013;26(3): 281-289.

44. Carrión JA, Navasa M, Forns, X. Retransplantation in patients with hepatitis $\mathrm{C}$ recurrence after liver transplantation. J Hepatol. 2010;53(5): 962-970.

45. Khong MJ, Chong P. Prevention and management of new-onset diabetes mellitus in kidney transplantation. Neth J Med. 2014;73(3):127-134.
Hepatic Medicine: Evidence and Research

\section{Publish your work in this journal}

Hepatic Medicine: Evidence and Research is an international, peerreviewed, open access journal covering all aspects of adult and pediatric hepatology in the clinic and laboratory including the following topics: Pathology, pathophysiology of hepatic disease; Investigation and treatment of hepatic disease; Pharmacology of drugs used for

\section{Dovepress}

the treatment of hepatic disease. Issues of patient safety and quality of care will also be considered. The manuscript management system is completely online and includes a very quick and fair peer-review system, which is all easy to use. Visit http://www.dovepress.com/ testimonials.php to read real quotes from published authors. 